\title{
Inflation, inflation uncertainty, and economic growth in emerging and developing countries: panel data evidence
}

\begin{abstract}
This paper investigates the relationship between inflation, inflation uncertainty, and economic growth in a panel of 94 emerging and developing countries. Based on the system generalized method of moments (SGMM) that controls for instrument proliferation, we discover the following results. First, when both the proliferation of instruments problem and the biased standard error in SGMM are accounted for, the results reveal that only in non-inflation crisis countries does inflation harm growth, while inflation uncertainty promotes growth. Empirical results, based on a three-regime model, confirm the negative growth effect of high inflation rates and the growth enhancing effect of low inflation. Second, the negative-level effect of not keeping inflation in check outweighs the positive effect from uncertainty in non-inflation crisis countries in all three regimes. Third, the existence of a positive effect of uncertainty about the inflation rate on growth through a precautionary motive is confirmed when inflation reaches moderate ranges (5.6-15.9\%). These findings are robust, although only for noninflation crisis countries, to a battery of diagnostic tests, including the issue of weak and the proliferation of instruments and biased standard error.
\end{abstract}

Keyword: Economic growth; Inflation; Inflation uncertainty; Three-regime model 